\title{
Seasonal variability in the distribution of microplastics in the coastal ecosystems and in some commercially important fishes of the Gulf of Mannar and Palk Bay, Southeast coast of India
}

\author{
Keziya James ${ }^{\mathrm{a}, \mathrm{b}, *}$, Kripa Vasant ${ }^{\mathrm{a}}$, Sikkander Batcha S.M. ${ }^{\mathrm{c}}$, Shelton Padua ${ }^{\mathrm{a}}$, \\ R. Jeyabaskaran ${ }^{\text {a }}$, S. Thirumalaiselvan ${ }^{\mathrm{c}}$, Vineetha G. ${ }^{\mathrm{a}}$, Liya V. Benjamin ${ }^{\mathrm{a}}$ \\ ${ }^{a}$ Central Marine Fisheries Research Institute (CMFRI), Kochi, Kerala, India \\ ${ }^{\mathrm{b}}$ Cochin University of Science and Technology, Kerala, India \\ ${ }^{\text {c } C e n t r a l ~ M a r i n e ~ F i s h e r i e s ~ R e s e a r c h ~ I n s t i t u t e, ~ M a n d a p a m, ~ T a m i l ~ N a d u, ~ I n d i a ~}$
}

\section{A R T I C L E I N F O}

\section{Article history:}

Received 26 May 2020

Received in revised form 3 November 2020

Accepted 22 November 2020

Available online 24 November 2020

\section{Keywords:}

Microplastic

Gulf of Mannar

Palk Bay

Concentration

Monsoon

Fishes

\begin{abstract}
A B S T R A C T
Impact of microplastic pollution on the marine environment and its biota is a major concern globally. Gulf of Mannar (GoM) and Palk Bay (PB) are two important biodiversity hotspots along the south-east coast of India. However, in the recent years the intense tourism and fishery activities have made the ecosystem and biota of these two ecologically significant coastal zones vulnerable to microplastic contamination. Hence, a comparative study on the seasonal distribution of microplastics in the surface waters, sediments, and in commercially important fishes were conducted to evaluate the threats imposed by microplastics on the environment and biota of both these coastal ecosystems. Microplastic distribution in the surface waters and sediments of GoM and PB exhibited conspicuous seasonal variation and showed positive correlation with the seasonal current patterns. In the surface waters of GoM, microplastics were abundant during the South West Monsoon whereas in PB it was high during the Early Winter Monsoon period. In the sediments of PB, microplastics was more during Spring Inter-monsoon and South West Monsoon whereas in GoM it was high during Late Winter Monsoon. Fragments, of size 1 to $5 \mathrm{~mm}$ formed the abundant microplastic type in the surface waters whereas in the sediments, fragments of size $<1 \mathrm{~mm}$ dominated. Of the gut content of the 613 fishes belonging to 12 families examined, microplastics were more in pelagic than demersal fishes with higher incidences in the family Clupeidae (42\%). Among the fishes studied, microplastic ingestion was more in Selaroides leptolepis (27.77\%), Sphyraena sp. (14.28\%), Pelates quadrilineatus (12\%), Caranx sp. (10.34\%), and Sphyraena barracuda (10\%).
\end{abstract}

(c) 2020 Elsevier B.V. All rights reserved.

\section{Introduction}

Plastics, in general, are considered as materials that resist biodegradation (Ryan, 2015), but may undergo fragmentation into monomers of smaller sizes upon mechanical action and UV radiation induced photo-oxidation (Cooper and Corcoran, 2010; Jambeck et al., 2015; Gewert et al., 2015; Tamara et al., 2017). Plastics having size $<5 \mathrm{~mm}$ are microplastics (Arthur et al., 2009), which in the recent years have emerged as a potent threat having immense impact on the marine ecosystem and its inherent biota. Microplastics, differing in their shape, properties and composition occur widely in the marine environment extending from the shorelines (Galgani et al., 2011; Carson et al., 2011; Hidalgo-Ruz

\footnotetext{
* Corresponding author at: Central Marine Fisheries Research Institute (CMFRI), Kochi, Kerala, India.

E-mail address: Keziyaj18@gmail.com (K. James).
}

et al., 2012), sea surface (Law et al., 2010; Collignon et al., 2012; Eriksen et al., 2013; Cozar et al., 2015) to the sea beds (Andrady, 2011; Van Cauwenberghe et al., 2013). Because of their smaller size and increased buoyancy, microplastics tend to float in the surface waters and eventually get transported to longer distances in the ocean through wind action and by water currents (Barnes et al., 2009).

In the marine ecosystem, the rate of accumulation of microplastics often vary with the proximity of urban activities, shore and coastal water uses, and wind and ocean current patterns (Galgani et al., 2015). Impacts of the microplastic pollution through ingestion and entanglement by marine invertebrates (Graham and Thompson, 2009; Thompson et al., 2004; Blessing et al., 2013; Van Cauwenberghe et al., 2013) and vertebrates (Boerger et al., 2010; Davison and Asch, 2011; Fossi et al., 2012) have already been reported from many parts of the world ocean.

Studies related to microplastic pollution and their consequences on the ecosystem and biota have been carried out in 
the Indian waters also (Sruthy and Ramasamy, 2016; James et al., 2020). The present study was particularly aimed at understanding the distribution of the microplastics in the surface waters, sediments, and in the guts of some commercially important fishes of the two ecologically relevant biodiversity hot spots (Kumaraguru et al., 2006a,b), Gulf of Mannar (GoM) and Palk Bay $(\mathrm{PB})$ in the northern Indian ocean. These coastal regions characterized by diverse habitats such as coral reef, sea grass meadows and mangrove forests, forms rich feeding and breeding grounds for a wide variety of aquatic organisms, especially many economically important fish species. Hence these regions are more explored for its fisheries and tourism values which subsequently forms the root cause of microplastic contamination (Krishnakumar et al., 2018). Taking into consideration the susceptibility of these sensitive coastal ecosystems to anthropogenic interferences, the state government has launched a "Green Rameswaram" project at Rameswaram Island from 2014 intending to create a clean, environment friendly and green Rameswaram island, aimed at preserving its ecology and marine biodiversity (Vasudeo et al., 2018). Though the larger macroplastic debris can be easily collected and removed, the pollution from smaller fragmented or UV degraded microplastics still pose a major challenge. Microplastics, because of their smaller sizes forms an easy target for ingestion by many aquatic organisms ranging from invertebrates to economically significant vertebrates, such as fishes. The ingestion of microplastics by marine fishes have been reported worldwide (Lusher et al., 2013; Lenz et al., 2016; Wieczorek et al., 2018). Since commercially exploited fishes forms the chief route of transfer of microplastics from the ecosystem to humans, an assessment of the rate of microplastic ingestion by the diverse fish community will provide a better understanding on the threats imposed by microplastic pollution on the ecosystem and to human health upon consumption.

Considering all these factors, the present study was focused to provide a baseline information on the distribution of the microplastics in the coastal waters and their ingestion by the major commercial fisheries to better understand the intensity of the impacts microplastic pollution generate on the ecosystem and biota of both these biodiversity hot spots in the northern Indian Ocean.

\section{Methodology}

\subsection{Study area}

The study was conducted in two shallow oceanic regions in the northern Indian Ocean, the GoM and the PB. GoM encompasses the territorial waters extending from Dhanushkodi in the north to Kanyakumari in the south and opens to the Arabian Sea in the west whereas the PB bounded by the GoM in the south and Bay of Bengal in the east. GoM supporting a rich and diverse aquatic organisms is notable for its rich pelagic fishery resources and also homes the first biosphere reserve in South East Asia, the Gulf of Mannar Biosphere Reserve forming an abode for about 3600 species of flora and fauna (Kumaraguru et al., 2006a,b). PB, with its well-established seagrass beds, tidal flats, and mangrove regions forms rich feeding and breeding area for a wide variety of aquatic organisms from fishes, prawns, and crabs and hence forms a rich demersal fishing ground.

For the study, sampling was carried out at four locations each in both GoM and PB. The sampling sites in the GoM were Mandapam, Vedhalai, Kilakkarai, and Dhanushkodi GoM whereas Agnitheertham, Villoondi Theertham Vil, North Pamban, and Dhanushkodi PB formed the sampling locations in the PB. (Figs. 1 and 2). Sampling in both these regions was conducted during Spring Inter-Monsoon (SIM - May), South West Monsoon (SWM - September), and in the Early Winter Monsoon (EWM - December) and Late Winter Monsoon (LWM - February) periods of 2019 .

\subsection{Surface water temperature, salinity and ocean current}

Sea Surface Temperature (SST) distribution in all the stations was estimated using standard mercury-filled centigrade thermometer whereas the salinity was measured using a refractometer. The ocean current data used in the present study were retrieved from the PODAAC-OSCAR (https://podaac.jpl.nasa.gov) archive.

\subsection{Microplastics in the surface waters}

Microplastics from the surface waters were sampled in triplicate by hauling a zooplankton net of mesh size $100 \mu \mathrm{m}$ at a speed of $1 \mathrm{knot}$ for $10 \mathrm{~min}$. The samples collected in the net and the cod-end were carefully transferred to a sampling bottle and fixed with $4 \%$ formalin onboard and were later manually sorted and enumerated under a stereomicroscope (40X) (James et al., 2020)

\subsection{Microplastics in the sediment}

For estimating the sediment microplastic distribution, triplicate samples of sediments were collected using a Van Veen grab $\left(0.025 \mathrm{~m}^{2}\right)$ from a depths ranging from $2-5 \mathrm{~m}$. Sediment samples were sieved using a stacked sieve $(5 \mathrm{~mm}$ and $1 \mathrm{~mm}$ ) and the retained samples were subsequently collected. In the laboratory, the sieved samples (retained in $1 \mathrm{~mm}$ sieve) were dried and transferred into $500 \mathrm{ml}$ beakers containing $200 \mathrm{ml}$ of saturated $5 \mathrm{M} \mathrm{NaCl}$ solution $(\mathrm{d}=1.15 \mathrm{~g} / \mathrm{ml})$ and stirred using a magnetic stirrer for $10 \mathrm{~min}$. Following this, the samples were allowed to settle for $5 \mathrm{~min}$ and the supernatants were vacuum filtered using filter paper of $0.4 \mu \mathrm{m}$ mesh size. The remaining samples in the beaker were treated again using $20 \mathrm{ml}$ hydrogen peroxide (30\%) until all organic contents were degraded. The supernatant was again filtered using a $0.4 \mu \mathrm{m}$ filter paper. After the filtration, the filter papers were dried and the microplastic retained was sorted and enumerated under the stereomicroscope (40X) (Masura et al., 2015; James et al., 2020)

\subsection{Microplastics in the fish gut}

Both pelagic and demersal fishes belonging to 12 families were collected from the fish landing centers of both GoM and PB. In the laboratory, the fishes were identified up to the species level followed by their length and weight measurements and dissection of their digestive tracts. The digestive tracts were subsequently treated by the wet peroxide oxidation method $\left(30 \% \mathrm{H}_{2} \mathrm{O}_{2}\right)$ at $75^{\circ} \mathrm{C}$ to dissolve all the organic contents. The digested samples were then filtered through a $0.4 \mu \mathrm{m}$ filter paper and dried. The microplastics retained in the filter paper were separated and enumerated under a stereomicroscope (40X) (Masura et al., 2015; James et al., 2020).

For estimating the microplastic ingestion, the gut content of about 613 fishes comprising of 25 species belonging to 12 families such as Clupeidae, Carangidae, Sphyraenidae, Leiognathidae, Sciaenidae, Terapontidae, Hemiramphidae, Scombridae, Siganidae, Cyanoglossidae, Lethrinidae and Mullidae were examined (Table 1).

\subsection{Identification of microplastics}

Microplastics collected from surface water, sediment, and fish guts were sorted according to their type and size and enumerated under the stereomicroscope (40×) (Hidalgo-Ruz et al., 2012; Lusher et al., 2017). 


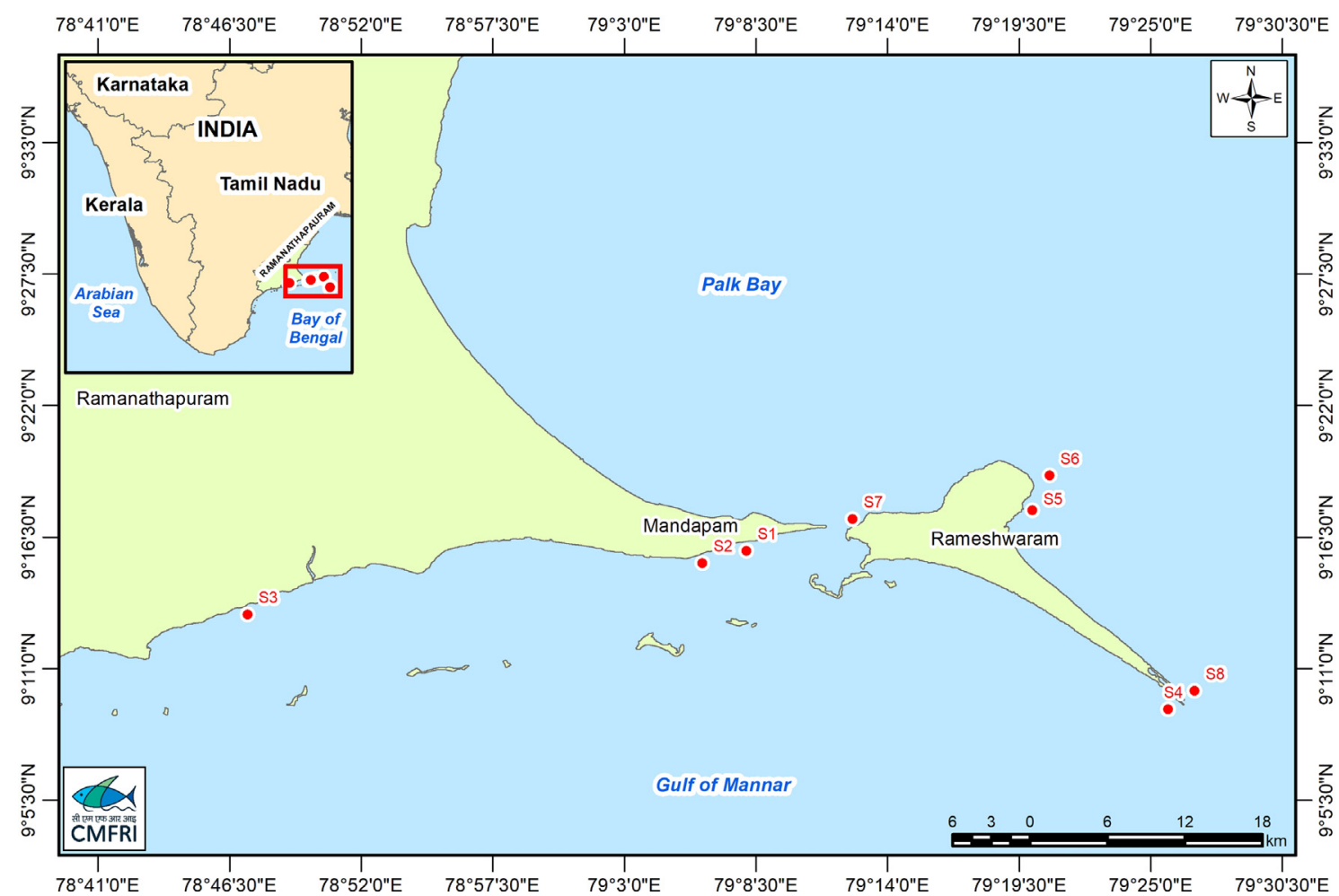

Fig. 1. Location map of the study area.

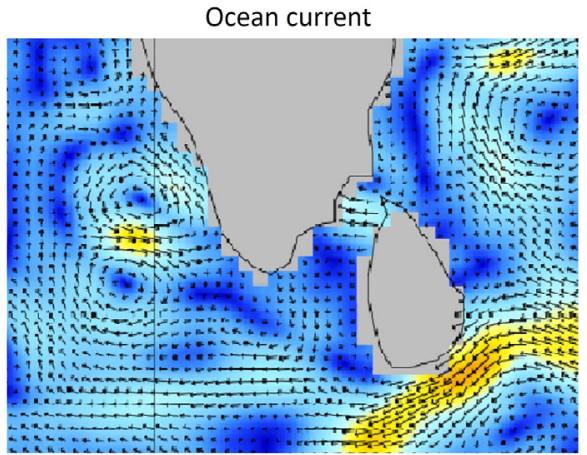

(a) LWM

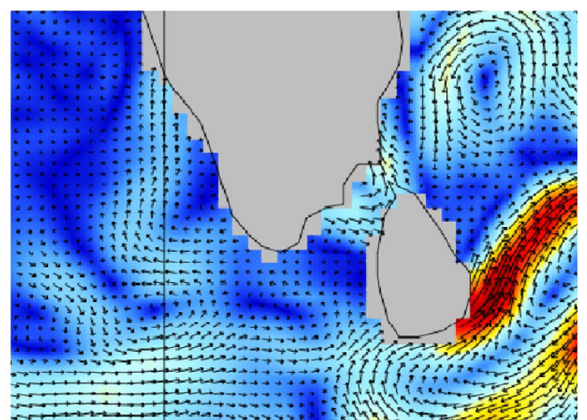

(c) SWM

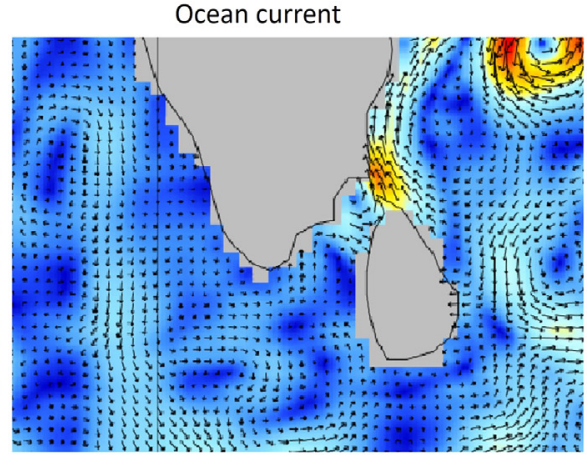

(b) SIM

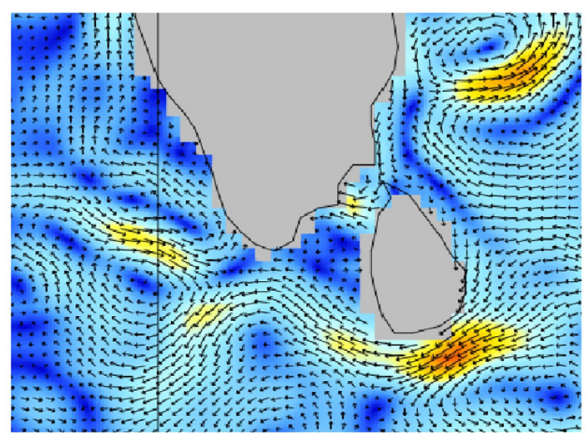

(d) EWM

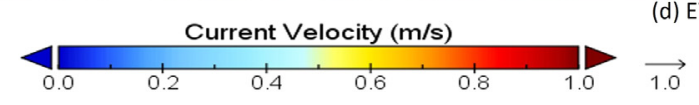

Fig. 2. Magnitude and direction of ocean currents in the GoM and PB region during the study period. 
Table 1

Details of fishes examined for the presence of microplastics.

\begin{tabular}{llllll}
\hline Family & Species & $\begin{array}{l}\text { No. of } \\
\text { individuals }\end{array}$ & Total length & Total weight & Habitat \\
\hline Clupeidae & Sardinella albella & 180 & $12.2 \pm 1.46$ & $17.4 \pm 4.38$ & Pelagic \\
& Sardinella sp. & 40 & $11 \pm 0.52$ & $16.8 \pm 4.82$ & Pelagic \\
& Caranx sp. & 29 & $13.5 \pm 0.72$ & $25.2 \pm 3.71$ & Demersal \\
& Atule mate & 24 & $16.9 \pm 0.56$ & $70.6 \pm 8.45$ & Pelagic \\
Carangidae & Decapterus russelli & 22 & $20.1 \pm 0.65$ & $93.1 \pm 5.69$ & Pelagic \\
& Tranchinotus blochii & 25 & $13 \pm 1.32$ & $52.5 \pm 3.31$ & Demersal \\
& Selaroides leptolepis & 18 & $12.3 \pm 1.23$ & $20.6 \pm 5.76$ & Pelagic \\
& Sphyraena sp. & 14 & $26.6 \pm 2.09$ & $143.3 \pm 4.88$ & Pelagic \\
Sphyraenidae & Sphyraena jello & 9 & $21.1 \pm 2.11$ & $47 \pm 14.9$ & Pelagic \\
& Sphyraena barracuda & 10 & $22.1 \pm 3.10$ & $68 \pm 20.39$ & Pelagic \\
Leiognathidae & Leiognathus equulus & 30 & $9.9 \pm 2.05$ & $16.2 \pm 8.88$ & Demersal \\
& Leiognathus sp. & 25 & $10.3 \pm 1.22$ & $16.8 \pm 6.76$ & Demersal \\
Sciaenidae & Kathala axillaris & 7 & $13.2 \pm 2.77$ & $31.4 \pm 19.79$ & Pelagic \\
& Otolithes sp. & 16 & $11.1 \pm 0.8 \pm$ & $45.6 \pm 8.13$ & Demersal \\
Terapontidae & Pelates quadrilineatus & 25 & $12.3 \pm 2.41$ & $23.3 \pm 18.11$ & Demersal \\
& Terapon puta & 13 & $12.1 \pm 1.58$ & $24.4 \pm 5.73$ & Demersal \\
Hemiramphidae & Hyporhamphus quoyi & 24 & $33.9 \pm 2.12$ & $88 \pm 5.76$ & Pelagic \\
& Hyporhamphus sp. & 15 & $25.1 \pm 1.41$ & $30 \pm 6.70$ & Pelagic \\
Scombridae & Hemirhamphus luktei & 11 & $23.8 \pm 1.05$ & $156.3 \pm 10.9$ & Pelagic \\
Siganidae & Rastrelliger sp. & 23 & $13.8 \pm 1.36$ & $43.4 \pm 9.68$ & Pelagic \\
Cyanoglossidae & Rastrelliger kanagurta & 21 & $11.5 \pm 0.88$ & $21.8 \pm 4.09$ & Demersal \\
Lethrinidae & Siganus canaliculatus & 7 & $12.3 \pm 0.76$ & $24.3 \pm 2.08$ & Demersal \\
Mullidae & Cynoglossus puncticeps & 3 & $13.8 \pm 1.23$ & $50 \pm 14.14$ & Demersal \\
& Lethrinus reticulatus & 9 & $13.5 \pm 1.49$ & $29.2 \pm 13.28$ & Demersal \\
\hline
\end{tabular}

\subsection{Contamination measures}

To avoid contamination the entire laboratory work was carefully handled by following standard protocols such as using laboratory coats, nitrile gloves, and glasswares washed with deionized water. During treatment, the sample beakers were covered using aluminum foil to avoid airborne plastic and textile fiber contamination.

\subsection{Statistical analysis}

Variability in the sea surface temperature, salinity and microplastic distribution along seasons was analyzed using One-way ANOVA. To understand the influence of currents on the microplastic distribution, correlation was carried out between the microplastic abundance and the respective current velocity in all the seasons. Both these statistical analysis was done using IBM SPSS statistics 23 software.

\section{Results}

\subsection{Seasonal distribution of temperature, salinity and microplastic}

The present study evidenced higher SST $\left(30 \pm 0.35^{\circ} \mathrm{C}\right)$ and salinity (37 $\pm 1.06 \mathrm{ppt})$ during SIM and minimum SST (26 \pm $0.98^{\circ} \mathrm{C}$ ) and salinity (35 $\pm 2.12 \mathrm{ppt}$ ) during EWM. SST, salinity and microplastic distribution exhibited significant seasonal variation (Table 2). SST and salinity showed significant variation in distribution along seasons in both GoM $(\mathrm{p}<0.05)$ and PB $(\mathrm{p}<0.01)$ (Table 2). With higher SST, a corresponding increase in the salinity was observed at a significance level of $\mathrm{p}=0.01$.

Microplastic distribution showed significant seasonal variation $(\mathrm{p}<0.05)$ in both surface waters and sediments of GoM whereas in $\mathrm{PB}$, the seasonal variation in the distribution of microplastics in surface waters and sediment was observed at significant levels of $\mathrm{p}<0.05$ and $\mathrm{p}<0.01$ levels respectively (Table 2 ).

\section{Table 2}

Results of One way - ANOVA depicting seasonal variation of abiotic variables and microplastic distribution in surface waters and sediments of GoM and PB.

\begin{tabular}{llll}
\hline & ANOVA (with season) & $f$-value & $p$-value \\
\hline \multirow{4}{*}{ GoM } & Temperature & 8.19 & .003 \\
& Salinity & 7.84 & .004 \\
& Microplastic in sediment & 4.64 & .022 \\
& Microplastic in surface water & 4.32 & .028 \\
\hline \multirow{4}{*}{ PB } & Temperature & 26.2 & .000 \\
& Salinity & 70.9 & .000 \\
& Microplastic in sediment & 4.15 & .031 \\
& Microplastic in surface water & 9.36 & .002 \\
\hline
\end{tabular}

\subsection{Distribution of microplastic with ocean current}

During LWM, the direction of the current was from the east towards the shoreline of $\mathrm{PB}$ with a maximum current velocity of $0.4-0.5 \mathrm{~m} / \mathrm{s}$ whereas in GoM the current speed got relatively lower to about $0.1-0.2 \mathrm{~m} / \mathrm{s}$. During SIM, the current flow was towards Sri Lanka with a notable drop in current velocity (0.3$0.4 \mathrm{~m} / \mathrm{s}$ ) in both PB and GoM. In GOM, the current speed was observed to be maximum during SWM $(0.4-0.5 \mathrm{~m} / \mathrm{s})$ whereas PB experienced relatively lower currents with a speed of $0.2-0.3 \mathrm{~m} / \mathrm{s}$ during this period. During EWM, the current velocity got higher in the PB $(0.5-0.6 \mathrm{~m} / \mathrm{s})$ and was in the tune of $0.2 \mathrm{~m} / \mathrm{s}$ in GoM but showed a reversal in its direction compared to the SWM (Fig. 2).

The distribution of microplastics in surface waters and sediment in both GoM and PB showed a strong positive correlation with the respective current velocity at a significant level of $\mathrm{p}<0.05$ (Fig. 3).

\subsection{Plastic debris in the beaches}

The study evidenced huge accumulation of plastic debris along the beaches of both the GoM and PB (Fig. 4). These were the outcomes of intense fishing and pilgrimage tourist activities along the beaches. The impact from the pilgrimage tourism activities was mostly concentrated along the stations such as Kilakkarai, Agnitheertham, Villoondi Theertham, Danushkodi GoM, 
GoM
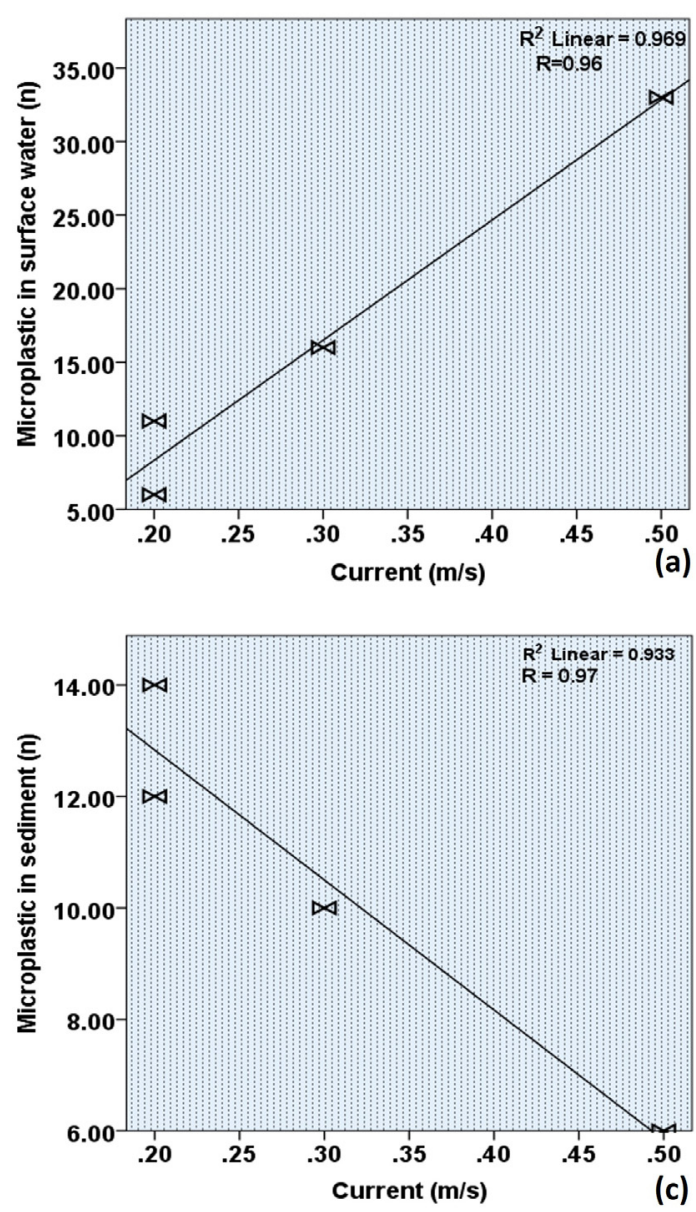

PB
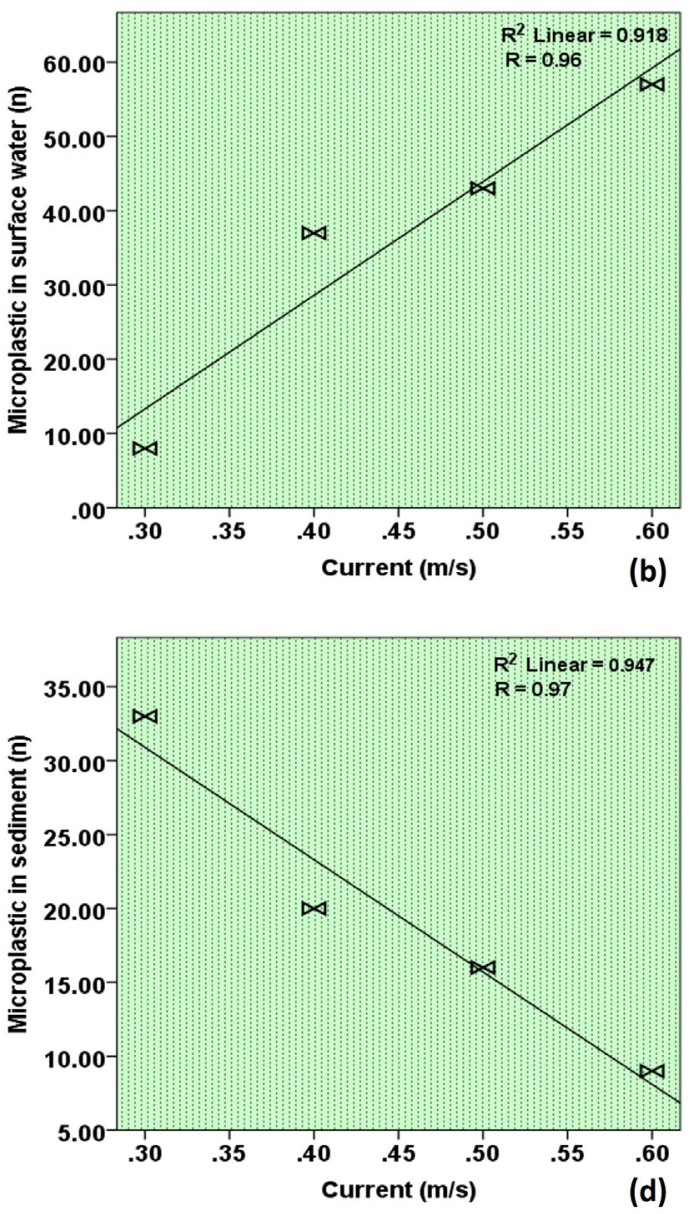

Fig. 3. Variation in distribution of microplastic with current in both surface water and sediment of GoM and PB.

and PB whereas the effects of regular fishing activities were found along the North Pamban, Vedhalai, Kilakkarai station locations. Danushkodi region along the coastlines of both GoM and PB is a major pilgrimage zone along the southeast coast of India. Along with this, small scale fishing activities such as shore siene fishing is also practiced intensely along this region in turn contributing to a large accumulation of fishing-related plastic litters like nets and floats along the beaches (Fig. 4a-i) and getting entangled in the coral beds of PB (Fig. 4j \& k). In Kilakkarai, litter accumulation was the consequent effects of the frequent repairing of fishing nets carried out by the fishers (Fig. $4 \mathrm{e}-\mathrm{f}$ ).

\subsection{Distribution of microplastic in surface water and sediments}

In both surface water and sediments, the seasonal distribution of microplastics (relative concentration) exhibited a see-saw pattern. Both the locations i.e. GoM and PB exhibited this see-saw pattern, but there was a 180 degree lag between these patterns showed by the GoM and PB. The percentage distribution of microplastics in both GoM and PB ranged from $20 \%-80 \%$ (Fig. 5). In the surface waters of $\mathrm{PB}$, the highest concentration (70\%-80\%) of microplastics was observed during the EWM and LWM whereas in GoM it was more prominent during the SWM (70\%-80\%) period (Fig. 5). In the sediment, the highest microplastic distribution in PB was observed during SIM and SWM (70\%-80\%) whereas in GoM it was observed to be high during LWM season (60\%-70\%) (Fig. 5).

The distribution of microplastics along each sampling location exhibited remarkable seasonal variations. Among the stations, the highest concentration of microplastics was observed in Kilakkarai (40\%-50\%) of GoM during the SWM and in North Pamban (30\%$40 \%$ ) of PB during both EWM and LWM periods (Fig. 6). In general, $\mathrm{PB}$ had higher microplastic abundance in its ecosystem compared to GoM.

\subsection{Type and size fraction}

Microplastics obtained were categorized into different types and sizes. Six microplastic types were obtained from the surface waters and sediment of GoM and PB with the predomination of fragments followed by filaments, pellets, fibers, films, and foams (Fig. 7).

Among the different microplastic size categories such as $<1 \mathrm{~mm}$ and $1-5 \mathrm{~mm}$, the $1-5 \mathrm{~mm}$ sized microplastics dominated the surface waters of both GoM and PB while in sediments, microplastics of size $<1 \mathrm{~mm}$ predominated (Fig. 8) .

\subsection{Microplastics in the fish gut}

The gut content of 613 individuals of fishes belonging to 12 different families were examined for the presence of microplastics. The fishes collected from the PB had higher microplastics in their guts compared to that of GoM.

Among the 14 species of fishes caught from PB, microplastics were observed in the gut of 6 species such as Selaroides leptolepis (27.8\%), Pelates quadrilineatus (12\%), Sphyraena barracuda (10\%), Sardinella albella (7.2\%), Leignathus equulus (3.3\%) and Sardinella 


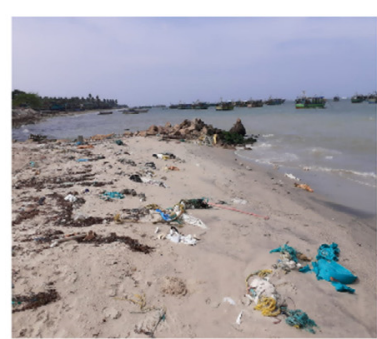

(a)

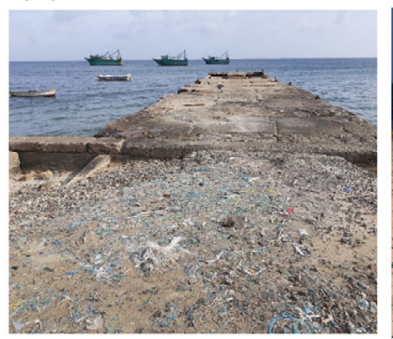

(e)

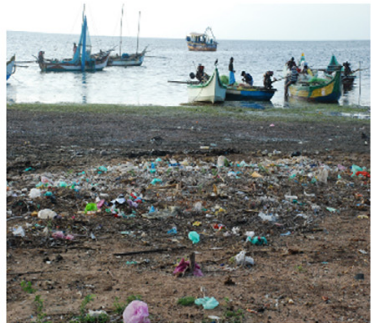

(b)

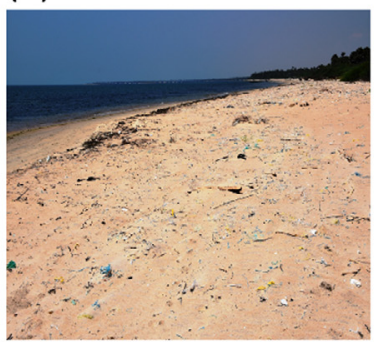

(f)

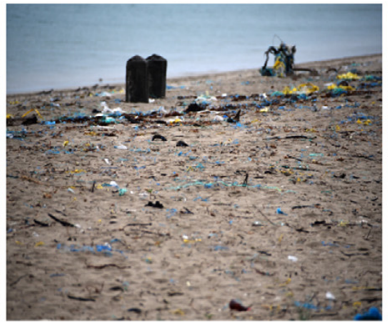

(c)

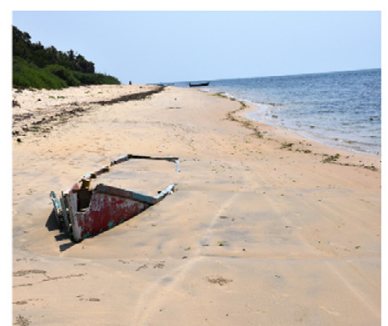

(g)

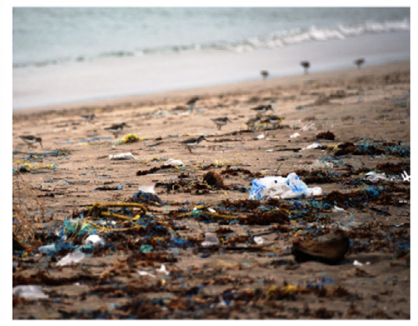

(d)

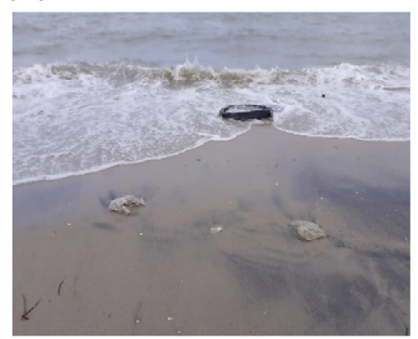

(h)

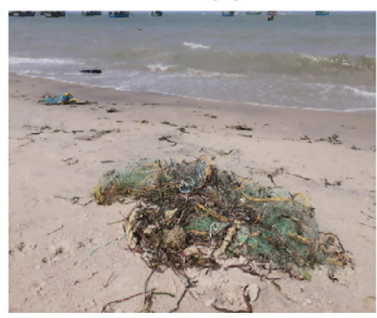

(i)

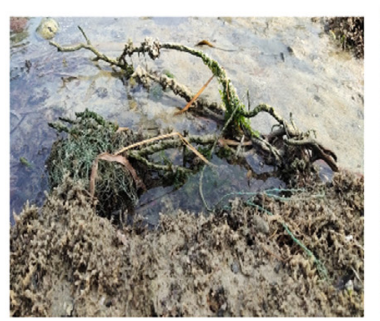

(j)

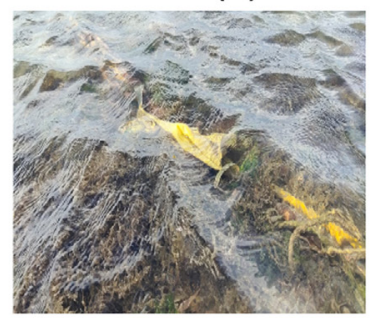

(k)

Fig. 4. Plastic debris lying scattered along the beaches of PB (a-b), GoM (e-f) and entangled along the coral beds (j \& k).

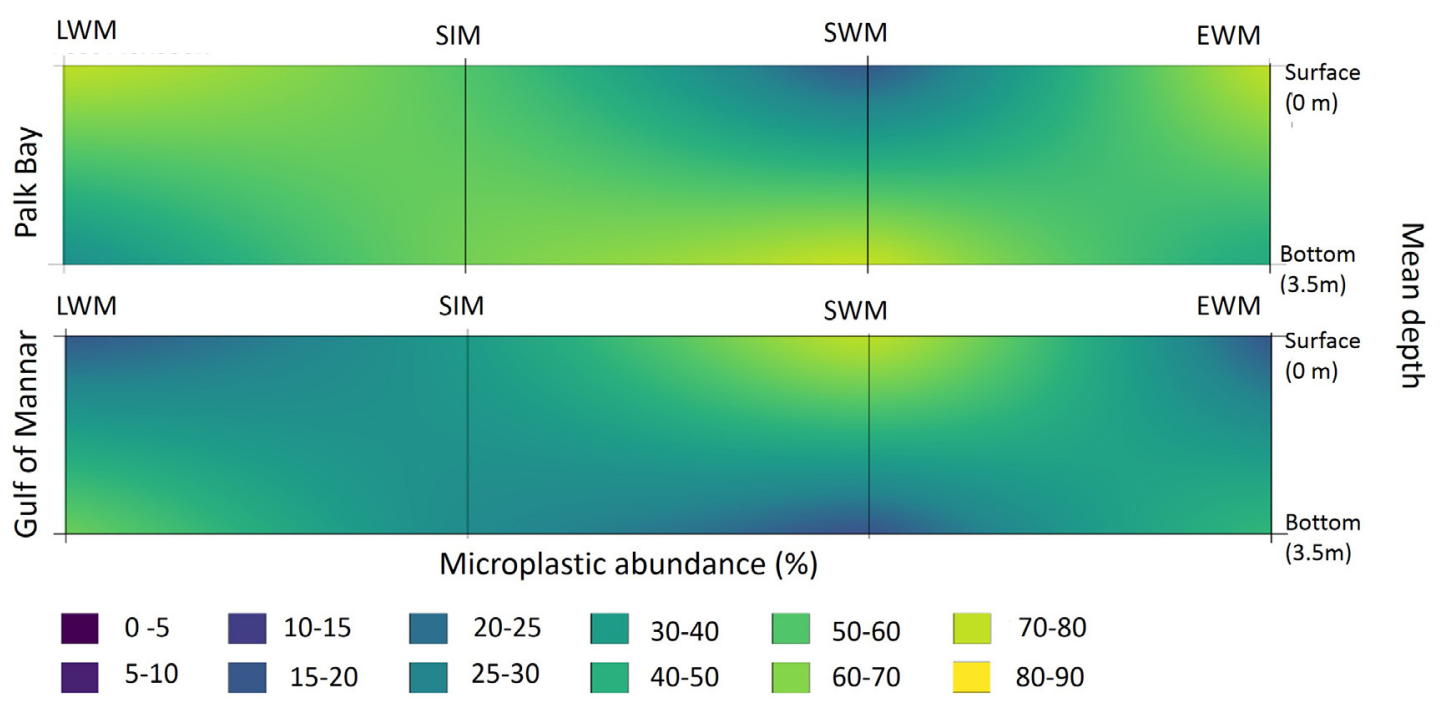

Fig. 5. Fluctuations of microplastic abundance in GoM and PB with the seasons.

sp. (2.5\%). In GoM, only 3 species of fishes such as Sphyraena sp. (14.3\%), Caranx sp. (10.3\%) and Sardinella albella (4\%) had microplastics in their gut out of the 12 species caught. (Table 3 ).

In both the ecosystems the pelagic fishes exhibited more microplastic ingestion compared to the demersal species (Fig. 9b).

While comparing the microplastic ingestion by the different fish species, it was observed that it was more among the family Clupeidae (42\%) followed by Carangidae (31\%), Terapontidae (14\%), Sphyraenidae (11\%) and Leiognathidae (4\%) (Fig. 9a).

\section{Discussion}

Microplastic pollution and threats imposed by them on the marine ecosystem and its inhabitants are now a major global concern. Among the varied marine habitats, coastal waters, and their associated beaches form one of the heavily impacted regions from microplastic pollution (Barnes and Milner, 2005). These regions being a major fishery zone often forms the prime location for fish landing and other fishing related activities. Furthermore, beaches being a major zone of coastal tourism and pilgrimage 


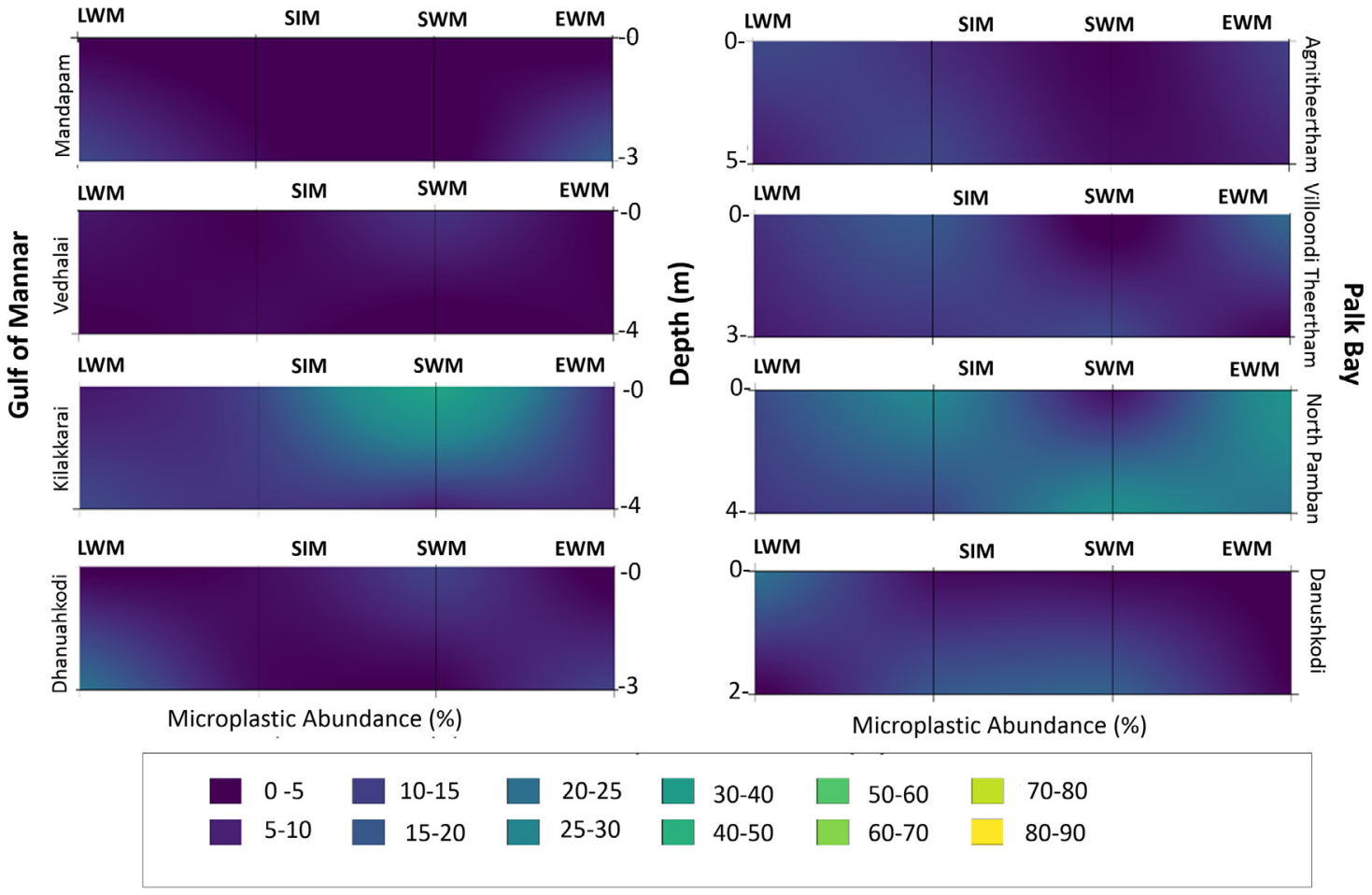

Fig. 6. Fluctuation of microplastic abundance in each station of GoM and PB with seasons.
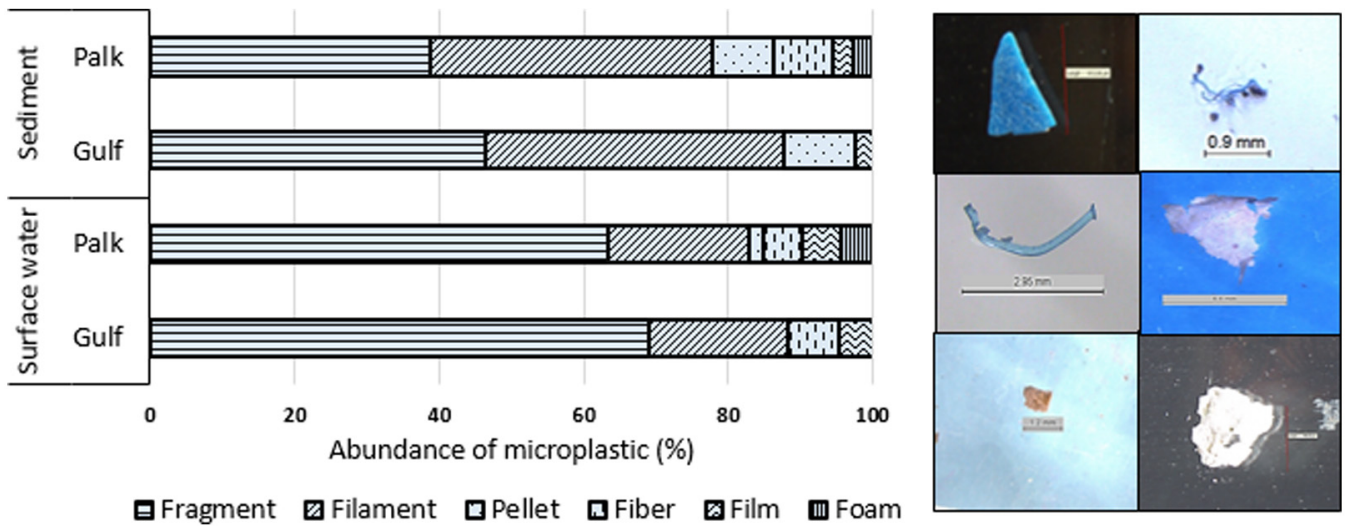

Fig. 7. The distribution of microplastics based on type.

activities get heavily impacted by pollution related to human interventions (Krishnakumar et al., 2018). The present study was conducted in GoM and PB, two major coastal water bodies in the northern Indian Ocean threatened by the impacts associated with fishing and tourism-related activities. Regions such as Kilakkarai, Agnitheertham, Villoondi Theertham, Danushkodi GoM, and PB formed the major pilgrimage and tourist spots whereas North Pamban, Vedhalai, Kilakkarai had more intense and routine fishing activities. Danushkodi region of both GoM and PB had both pilgrimage and shore siene activities. All these regular anthropogenic activities might have led to the vast accumulation of plastic litters in the beaches. These plastic litters accumulated in the beaches might have entered the coastal waters either through monsoonal runoff or with the tidal incursion causing serious impacts on the coastal habitats and its biota. A study conducted at a popular tourist destination of South Korea reported heavy rain and subsequent runoff as a major factor behind the unusually high level of marine litters reaching the marine ecosystem from the beaches (Jang et al., 2014).
Debris from fishing gears accounts for the high percentage of plastic pollution in the fishing zones (Lee et al., 2006; Galgani et al., 2000; Newman et al., 2015). Litter from fishing gears forming the dominant source of plastic debris was reported along the California coasts (Moore and Allen, 2000). Plastic litters and ghost nets entering the seagrass beds and coral reefs often threaten the marine fauna like dugongs and turtles through entanglement. Entanglement in lost fishing gear and ropes impedes the movement, feeding and, respiration of aquatic organisms (Laist, 1997; Andrady, 2011; Kunhn et al., 2015) besides affecting their predatory activities (Laist, 1997). The marine plastic debris is also reported to affect coral growth (Senthilnathan et al., 2018) and even lead to their partial mortality through physical damages brought it by the deposition of plastic debris (Ranith et al., 2018). To reduce this risk, one of the best practice guidelines to be adopted is the Fishing-for-Litter scheme (OSPAR, 2007) for efficient waste management related to fisheries.

The shorelines Kilakkarai of GoM was found to be littered by sewage pipes and by discarded fishing net lines which subsequently reaches the coastal waters through wind action or runoff 
Table 3

Percentage abundance of microplastics obtained from the fish gut.

\begin{tabular}{llrc}
\hline Location & Species & $\begin{array}{l}\text { No. of individuals } \\
(\mathrm{n})\end{array}$ & $\begin{array}{l}\text { Microplastics } \\
(\%)\end{array}$ \\
\hline \multirow{4}{*}{ Sardinella albella } & 100 & 4 \\
& Caranx sp. & 29 & 10.34 \\
Sphyraena sp. & 14 & 14.28 \\
Leiognathus sp. & 25 & 0 \\
& Kathala axillaris & 7 & 0 \\
Atule mate & 24 & 0 \\
Rastrelliger sp. & 23 & 0 \\
Sphyraena jello & 9 & 0 \\
Hemirhamphus luktei & 11 & 0 \\
Otolithes cuvieri & 16 & 0 \\
Hyporhamphus quoyi & 24 & 0 \\
Rastrelliger kanagurta & 21 & 0 \\
\hline Leiognathus equulus & 30 & 3.33 \\
Decapterus russelli & 22 & 0 \\
Sardinella sp. & 40 & 2.5 \\
Sardinella albela & 80 & 7.5 \\
Terapon puta & 13 & 0 \\
Siganus canaliculatus & 7 & 0 \\
Cynoglossus puncticeps & 3 & 0 \\
Hyporhamphus quoyi & 15 & 0 \\
Selaroides leptolepis & 18 & 27.77 \\
Lethrinus recticulatus & 9 & 0 \\
Upeneus sp. & 13 & 0 \\
Sphyraena barracuda & 10 & 12 \\
Tranchinotus blochii & 25 & 0 \\
Pelates quadrilineatus & 25 & \\
\hline
\end{tabular}

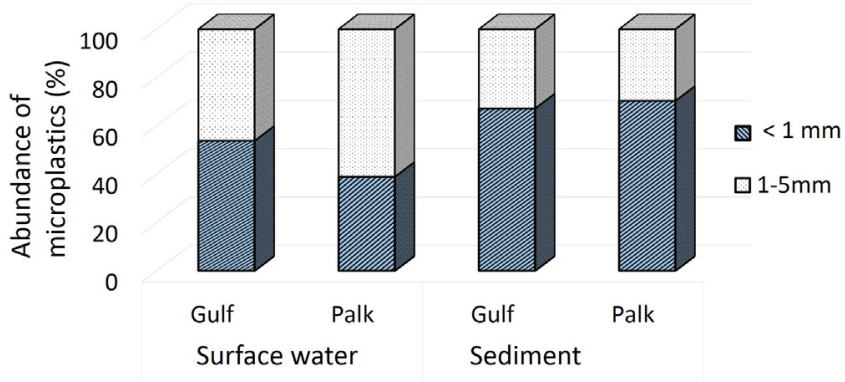

Fig. 8. Distribution of microplastics based on size.

from beaches. The large quantities of discarded nets along the shoreline further aggravate the threat of microplastic pollution by weathering. Outfalls and treated effluents from wastewater treatment plants linked to microplastic pollution in the coastal environment further justify the view (Browne et al., 2011; Murphy et al., 2016; Wright et al., 2013).

The GoM is predominantly influenced by the SWM whereas PB by the LWM monsoon. The seasonal distribution of microplastic (relative concentration) in surface waters and the sediments exhibited a see-saw pattern. In both GoM and PB, the maximum number of microplastic in the surface waters was encountered when the sea was rough whereas in the sediments it exhibited a reverse trend with higher microplastic numbers during calm sea conditions. Ocean currents and wind patterns have a major role in the suspension and re-suspension of microplastics in the coastal waters. Higher microplastic distribution in the surface waters of GoM and PB during the SWM and EWM respectively might have resulted by this process of re-suspension from sediments by wind and current action. The higher wind action during the monsoon periods often results in swells and rolling in the open ocean leading to the development of rough sea conditions. The rolling and swelling subsequently result in the re-suspension of sediments in these shallow coastal waters leading to the suspension of microplastics in the water column thus resulting in a decrease in the microplastic abundance in sediments and a corresponding increase in their abundance in the surface waters during monsoon. In contrast, at periods of calm sea conditions, the microplastics settles to the bottom either through physical density process or through biofouling activities (Wright et al., 2013). The buoyancy of the floating microplastics is decreased either through weathering and biofouling (Barnes et al., 2009; Lobelle and Cunliffe, 2011), mineral adsorption (Corcoran et al., 2015) or by incorporation of microplastics into fecal pellets (Cole et al., 2016) leading to their higher settling in the deeper water column (Debrot et al., 2014) and subsequent sedimentation to the seafloor (Galgani et al., 1996; Law et al., 2010; Andrady, 2011; Galgani and Lecornu, 2004). The positively buoyant items tend to accumulate near the sea surface and get transported by winds and surface water currents, whereas negatively buoyant items sink out of the water column to the sediments below (Van Cauwenberghe et al., 2013). The contrasting trend in the microplastic distribution in surface waters and sediments of GoM and $\mathrm{PB}$ with a prominent see-saw pattern in their abundance can be linked to this seasonal reversal of wind circulation and surface current patterns in GoM and PB and the consequent sea conditions (Gowthaman et al., 2013).

Among the microplastic types, fragments predominated in numbers both in GoM and PB followed by filaments, pellets, fibers, films, and foams. These secondary microplastics might be the end products of weathering of plastic bags, bottles, fishing nets, ropes, thermocoal etc. Plastic breaks into smaller particles through fragmentation by the action of light, heat and oxygen, water, and by organisms (Andrady, 2011). While considering the size category of microplastics, the highest number of microplastic were of the size range between 1 to $5 \mathrm{~mm}$ both in GoM and PB whereas, in sediments, the $<1 \mathrm{~mm}$ sized microplastics dominated. As the size, shape, and density of microplastic (Cole et al., 2016) determine their settling and buoyancy in the marine ecosystems, the denser microplastics might have settled more compared to the lighter ones which remained floating in the surface waters. Thus along with wind and water currents, the characteristics of the microplastics have a critical role in their effective dispersal and sedimentation in the oceanic regions (Thompson, 2015).

Carpenter et al. (1972) were the first to report on plastic ingestion by marine fishes which later on led to several studies substantiating the occurrence of microplastics in the fish guts (Boerger et al., 2010; Davison and Asch, 2011; Lusher et al., 2013; Lenz et al., 2016; Wieczorek et al., 2018). The gut contents of 613 individuals of fishes belonging to 12 families were analyzed for the presence of microplastics. It was observed that the fish species collected from $P B$ had the highest number of microplastics in their gut compared to that from GoM. As PB had more microplastic abundance in both surface waters and sediments than GoM, the chances of microplastic ingestion by fishes of PB was more.

Furthermore, the higher incidence of microplastics in the pelagic fishes compared to demersal indicated the increased availability of microplastics in the surface waters compared to the sediments. Among the examined fishes, species belonging to family Clupeidae had maximum number of microplastics in their gut. These pelagic fishes characterized by indiscriminate filter-feeding patterns have higher chances to ingest the neutrally buoyant plastic particles compared to others (Rummel et al., 2016). Active feeding of microplastics may also happen as they often misjudge the visually similar microplastics to their prey (Mizraji et al., 2017).

Demersal fishes like Pelates quadrilineatus and Leiognathus equulus mostly prey upon small or narrow-bodied organisms like copepods and polychetes inhabiting the benthic realm (Warburton and Blaber, 1992). The higher microplastics in their gut might 

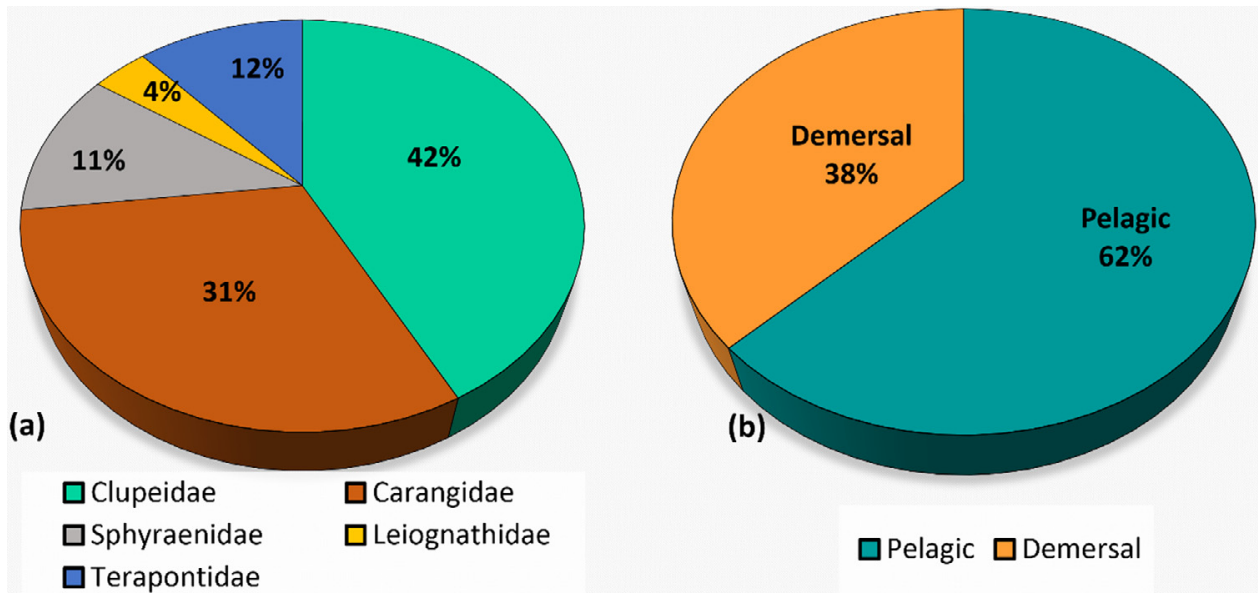

Fig. 9. Percentage contribution of microplastics in 613 individuals of fishes belonging to different (a) family and (b) habitats.

have resulted from the accidental intake of sediment microplastics while feeding. Many fishes are opportunistic feeders, showing marked individual preferences in prey consumption (Bryan and Larkin, 1972). The fish, Sphyraena sp. is an ambush predator which attack and ingest their prey using sharp jaws (Ramachandran et al., 2006). Caranx sp. is also predominantly carnivorous preying mostly on the juveniles of sardines, anchovies, and other fin-fishes (Abdussamad et al., 2008). Hence the microplastic incidence in their gut indicates the accidental intake through the ingestion of the whole prey or the microplastics adhering on their prey (Jovanovic, 2017; Ryan et al., 2016). Thus, the voracious feeding habits of these generalist predatory fishes often result in the unintentional ingestion of plastic debris. Some predatory fishes tend to bite their prey before ingestion and have been observed to attack the drifting plastics (Carson et al., 2013) which can also consequently lead to the ingestion of microplastics. Ingestion of such non-degradable plastic materials increases the risk of digestive tract blockages subsequently leading to starvation and mortality in marine vertebrates (Laist, 1997).

\section{Conclusion}

The study highlighted the alarming signals of increased incidences of microplastics in the highly productive and biodiverse coastal ecosystems in the northern Indian ocean. The surface water, sediments, and some commercially significant fishes of GoM and PB of the Southeast coast of India showed the presence of microplastics. Microplastic abundance was more in the coastal ecosystems and in fishes of PB compared to GoM. Pelagic fishes had more microplastics in their gut than demersal and with the family Clupeidae exhibiting higher microplastic ingestion. These pelagic fishes being the most preferred prey items by both higher trophic levels and by humans, there is a chance of its bioaccumulation in the food web and in humans upon consumption. Hence it becomes utmost essential to spread awareness on microplastic pollution among the local population, and also to formulate management plans and recommendations to reduce the practice of discarding damaged fishnets in the beaches. Considering the ecological relevance and sensitivity of the PB and GoM characterized by extensive seagrass beds and coral reefs, efficient plastic waste management practices need to be implemented at the earliest especially in the regions of intense tourist and fishing activities along its coasts.

\section{CRediT authorship contribution statement}

Keziya James: Investigation, Methodology, Resources, Formal analysis, Writing. Kripa Vasant: Administration, Supervision, Validation, Review and editing. Sikkander Batcha S.M.: Investigation, Resourses. Shelton Padua: Conceptualization, Software, Formal analysis, Review and editing. R. Jeyabaskaran: Resources, Review and editing. S. Thirumalaiselvan: Investigation, Resources. Vineetha G.: Review and editing. Liya V. Benjamin: Resources.

\section{Declaration of competing interest}

The authors declare that they have no known competing financial interests or personal relationships that could have appeared to influence the work reported in this paper.

\section{Acknowledgment}

Authors acknowledge CUSAT and CMFRI for providing institutional support for this work. Special gratitude to UGC for the research fellowship provided to Ms. Keziya James, JRF (2017), CMFRI, Kochi. Our sincere gratitude to Dr. Rengarajan Jayakumar, Principal Scientist, CMFRI, Mandapam, for providing all lab facilities at CMFRI Mandapam. The first author would like to thank the family members for their immense support and help received during the entire work especially Ajai Raj J, Abin D James, Soniya George, Binto Babu, Jithin George and Gladson Mam George.

\section{Appendix A. Supplementary data}

Supplementary material related to this article can be found online at https://doi.org/10.1016/j.rsma.2020.101558.

\section{References}

Abdussamad, E.M., Mohamad, K.H., Balasubramanian, 2008. Distribution, biology and behaviour of gaint trevally Caranx ignobilis- a candidate species for mariculture. Bangladesh. J. Fish. Res. 12 (1), 89-94.

Andrady, A.L., 2011. Microplastics in the marine environment. Mar. Pollut. Bull. 62 (8), 1596-1605. http://dx.doi.org/10.1016/j.marpolbul.2011.05.030.

Arthur, C., Baker, J., Bamford, H., 2009. Proceedings of the International Research Workshop on the Occurrence. Effects, and Fate of Microplastic Marine Debris, September 9-11, 2008.

Barnes, D.K., Galgani, F., Thompson, R.C., Barlaz, M., 2009. Accumulation and fragmentation of plastic debris in global environments. Philos. Trans. R. Soc. B 364 (1526), 1985-1998. http://dx.doi.org/10.1098/rstb.2008.0205.

Blessing, E., Wegner, A., Foekema, E.M., Van den Heuvel-Greve, M.J., Koelman, A.A., 2013. Effects of microplastic on fitness and PCB bioaccumulation by the Lungworm Arenicola marina. Environ. Sci. Technol. 47, 593-600. 
Boerger, M.C., Lattin, G.L., Moore, S.L., Moore, C.J., 2010. Plastic ingestion by planktivorous fishes in the North Pacific Central Gyre. Mar. Pollut. Bull. 60, 2275-2278. http://dx.doi.org/10.1016/j.marpolbul.2010.08.007.

Browne, M.A., Crump, P., Niven, S.J., Teuten, E.L., Tonkin, A., Galloway, T., Thompson, R.C., 2011. Accumulations of microplastic on shorelines worldwide: sources and sinks. Environ. Sci. Technol. 45, 9175-9179.

Bryan, J.E., Larkin, P.A., 1972. Food specialisation by individual trout. J. Fish. Res. 29, 1615-1624.

Carpenter, E.J., Anderson, S.J., Harvey, G.R., Miklas, H.P., Peck, B.B., 1972. Polystyrene spherules in coastal waters. Science 178, 749-750.

Carson, H.S., Nerheim, M.S., Carroll, K.A., Eriksen, M., 2013. The plastic-associated microorganisms of the North Pacific Gyre. Mar. Pollut. Bull. 75 (1), 126-132.

Carson, H.S., Steve, L.C., Mathew, J.K., Karla, J.M., 2011. Small plastic debris changes water movement and heat transfer through beach sediments. Mar. Pollut. Bull. 62 (8), 1708-1713.

Cole, M., Lindeque, P.K., Fileman, E., Clark, J., Lewis, C., Halsband, C., Galloway, T.S., 2016. Microplastics alter the properties and sinking rates of zooplankton faecal pellets. Environ. Sci. Technol. 50 (6), 3239e3246. http: //dx.doi.org/10.1021/acs.est.5b05905.

Collignon, A., Hecq, J., Galgani, F., Voisin, P., Goffard, A., 2012. Neustonic microlastics and zooplankton in the western Mediterranean sea. Mar. Pollut. Bull. 64, 861-864.

Cooper, D.A., Corcoran, P.L., 2010. Effects of mechanical and chemical processes on the degradation of plastic beach debris on the island of Kauai, Hawaii. Mar. Pollut. Bull. 60, 650-654.

Corcoran, P.L., Norris, T., Ceccanese, T., Walzak, M.J., Helm, P.A., Marvin, C.H., 2015. Hidden plastics of Lake Ontario, Canada and their potential preservation in the sediment record. Environ. Pollut. 204, 17e25. http://dx.doi.org/ 10.1016/j.envpol.2015.04.009.

Cozar, A., Sanz-Martín, M., Martí, E., Gonzalez-Gordillo, J.I., Ubeda, B., Gálvez, J.Á., Irigoien, X., Duarte, C.M., 2015. Plastic accumulation in the mediterranean sea. PLoS One 10, 1-12.

Davison, P., Asch, R.G., 2011. Plastic ingestion by mesopelagic fishes in the North Pacific Subtropical Gyre. Mar. Ecol. 432, 173-180. http://dx.doi.org/10.3354/ meps09142.

Debrot, A., Vinke, E., van der Wende, G., Hylkema, A., Reed, J., 2014. Deepwater marine litter densities and composition from submersible video-transects around the ABC-islands, Dutch Caribbean. Mar. Pollut. Bull. 88 (1-2), 361-365.

Eriksen, M., Maximenko, N., Thiel, M., Cummins, A., Lattin, G., Wilson, S., 2013. Plastic marine pollution in the South Pacific subtropical gyre. Mar. Pollut. Bull. 68, 71-76.

Fossi, M.C., Panti, C., Guerranti, C., Coppola, D., Giannetti, M., Marsili, L., Minutoli, R., 2012. Are baleen whales exposed to the threat of microplastics? A case study of the Mediterranean fin whale (Balaenoptera physalus). Mar. Pollut. Bull. 64 (11), 2374-2379, http://dx.doi.org/10.1016/j.marpolbul.2012. 08.013. Epub 2012 Sep 7.

Galgani, F., Fleet, D., van Franeker, J.A., Hanke, G., De Vrees, L., Katsanevakis, S., 2011. Monitoring marine litter within the European marine strategy framework directive (MSFD): Scientific and technical basis. In: 5th International Marine Debris Conference, Honolulu, Hawaii, pp. 164-168). 20-25.

Galgani, F., Hanke, G., Maes, T., 2015. Global distribution, composition and abundance of marine litter. In: Marine Anthropogenic Litter. pp. 29-56. http://dx.doi.org/10.1007/978--3--319--16510--3_2.

Galgani, F., Lecornu, F., 2004. Debris on the sea floor at 'Hausgarten': In the expedition ARKTIS XIX/3 of the research vessel POLARSTERN in 2003. Berichte Polar Meeresforsch 488, 260-262.

Galgani, F., Pleaute, J., Mouguedet, P., Souplet, A., Verin, Y., Carpentier, A., Gorague, Latrouite, D., Andral, B., Cadiou, Y., Mahe, J.C., Poulard, J.C., Nerisson, 2000. Litter on the sea floor along European coasts. Mar. Pollut. Bull. 40, 516-527. http://dx.doi.org/10.1016/S0025--326X(99)00234--9.

Galgani, F., Souplet, A., Cadiou, Y., 1996. Accumulation of debris on the deep sea floor off the French Mediterranean coast. Mar. Ecol. Prog. Ser. 142, 225-234.

Gewert, B., Plassmann, M.M., MacLeod, M., 2015. Pathways for degradation of plastic polymers floating in the marine environment. Environ. Sci. Processes Impacts 17, 1513-1521.

Gowthaman, R., Sanil Kumar, V., Dwarakish, G., Mohan, S., Singh, J., Kumar, K., 2013. Waves in Gulf of Mannar and Palk Bay around Dhanushkodi, Tamil Nadu, India. Current Sci. 104.

Graham, E.R., Thompson, J.T., 2009. Deposit- and suspension-feeding sea cucumbers (Echinodermata) ingest plastic fragments. J. Exp. Mar. Biol. Ecol. 368, 22-29.

Hidalgo-Ruz, V., Gutow, L., Thompson, R.C., Thiel, M., 2012. Microplastics in the marine environment: a review of the methods used for identification and quantification. Environ. Sci. Technol. 46, 3060-3075. http://dx.doi.org/ 10.1021/es2031505, https://podaac.jpl.nasa.gov.

Jambeck, J.R., Geyer, R., Wilcox, C., Siegler, T.R., Perryman, M., Andrady, A., Narayan, R., Law, K.L., 2015. Plastic waste inputs from land into the ocean. Science 347 (6223), 768-771. http://dx.doi.org/10.1126/science.1260352.
James, K., Kripa, V., Shelton, P., Vineetha, G., Abilash, K.S., Jeyabaskaran, R., Akhil, B., Seban, J., 2020. An assessment of microplastics in the ecosystem and selected commercially important fishes off Kochi, south eastern Arabian Sea, India. Mar. Pollut. Bull. 154, http://dx.doi.org/10.1016/j.marpolbul.2020. 111027.

Jang, Y.C., Lee, J., Hong, S., Lee, J., Shim, W., Song, Y., 2014. Sources of plastic marine debris on beaches of Korea: More from the ocean than the land. Ocean Sci. J. 49, 151-162. http://dx.doi.org/10.1007/s12601--014--0015--8.

Jovanovic, B., 2017. Ingestion of microplastics by fish and its potential consequences from a physical perspective: Potential Consequences of Fish Ingestion of Microplastic. Integrated Environ. Assess. Manag. 13 (3), 510-515, 13, 510-515. http://dx.doi.org/10.1002/ieam.1913.

Krishnakumar, S., Srinivasalub, S., Saravanana, P., Vidyasakarc, A., Magesh, N.S., 2018. A preliminary study on coastal debris in Nallathanni Island, Gulf of Mannar Biosphere Reserve, Southeast coast of India. Mar. Pollut. Bull. 131, 547-551. http://dx.doi.org/10.1016/j.marpolbul.2018.04.026.

Kumaraguru, A.K., Edwin, J.V., Marimuthu, N., Jerald, W.J., 2006a. Scientific Information on Gulf of Mannar - A Bibliography. Centre for Marine and Coastal Studies, Madurai Kamaraj University, Madurai, Tamilnadu, India, p. 656.

Kumaraguru, A., Joseph, E., Marimuthu, N., Wilson, J., 2006b. Scientific Information on Gulf of Mannar - A Bibliography. Gulf of Mannar Marine Biosphere Reserve Trust.

Laist, D.W., 1997. Impacts of marine debris: entanglement of marine life in marine debris including a comprehensive list of species with entanglement and ingested records. In: Coe, J.M., Rogers, D.B. (Eds.), Marine Debris: Sources, Impacts and Solutions. Springer Verlag, New York, pp. 99-140.

Law, K.L., Moret-Ferguson, S., Maximenko, N.A., Proskurowski, G., Peacock, E.E., Hafner, J., Reddy, C.M., 2010. Plastic accumulation in the north atlantic subtropical gyre. Science 329, 1185-1188.

Lee, D., Hyeon-Seo, C., Sun-Beom, J., 2006. Distribution characteristics of marine litter on the sea bed of the East China Sea and the South Sea of Korea. Est. Coast. Shelf Sci. 70, 187-194. http://dx.doi.org/10.1016/j.ecss.2006.06.003.

Lenz, R., Enders, K., Beer, S., Sorensen, T.K., Stedmon, C.A., 2016. Analysis of Microplastic in the Stomachs of Herring and cod from the North Sea and Baltic Sea. DTU Aqua National Institute of Aquatic Resources, http://dx.doi. org/10.13140/RG.2.1.4246.6168.

Lobelle, D., Cunliffe, M., 2011. Early microbial biofilm formation on marine plastic debris. Mar. Pollut. Bull. 62, 197-200.

Lusher, A.L., McHugh, M., Thompson, R.C., 2013. Occurrence of microplastics in the gastrointestinal tract of pelagic and demersal fish from the English channel. Mar. Pollut. Bull. 67, 94-99. http://dx.doi.org/10.1016/j.marpolbul. 2012.11.028.

Lusher, A.L., Welden, N.A., Sobral, P., Cole, M., 2017. Sampling, isolating and identifying microplastics ingested by fish and invertebrates. Anal. Methods 9, 1346-1360.

Masura, J., Baker, J., Foster, G., Arthur, C., 2015. In: Herring, C. (Ed.), Laboratory Methods for the Analysis of Microplastics in the Marine Environment: Recommendations for Quantifying Synthetic Particles in Waters and Sediments. NOAA Technical Memorandum.

Mizraji, R., Ahrendt, C., Pere-Venegas, D., Vargas, J., Pulgar, J., Aldana, M., Patricio, O.F., Duarte, C., Galbán-Malagón, 2017. Is the feeding type related with the content of microplastics in intertidal fish gut?. Mar. Pollut. Bull. 116, 498-500. http://dx.doi.org/10.1016/j.marpolbul.2017.01.008.

Moore, S.L., Allen, M.J., 2000. Distribution of anthropogenic and natural litter on the mainland shelf of the Southern California Bight. Mar. Pollut. Bull. 40, 83-88. http://dx.doi.org/10.1016/S0025--326X(99)00175--7.

Murphy, F., Ewins, C., Carbonnier, F., Quinn, B., 2016. Wastewater treatment works (WWTW) as a source of microplastics in the aquatic environment. Environ. Sci. Technol. 50 (11), 5800-5808.

Newman, S., Emma, W., Andrew, F., Patrick, T.B., Schweitzer, J., 2015. The economics of marine litter. Marine Anthropogenic Litter, http://dx.doi.org/ 10.1007/978--3--319--16510--3_14.

OSPAR, 2007. OSPAR Pilot Project 2000-2006 on Monitoring Marine Beach Litter. Final Report. OSPAR Report 306, p. 74.

Ramachandran, D., Mohan, M., Sankar, T.V., 2006. Physicochemical characteristics of muscles proteins from barracuda (Sphyraena jello) of different weight groups. LWT. Food Sci. Technol. 40, 1418-1426.

Ranith, R., Kripa, V., Jeyabaskaran, R., Senthilnathan, L., Manchendrinanathan, M., 2018. Marine Debris Impedes Coral Reef Endurance- A Situational Remark from the Rameswaram Island, Palk Bay, Indian Ocean. COMAD 2018. Marine Biological Association of India, pp. 39-40.

Ryan, P.G., 2015. A brief history of marine litter research. In: Bergmann, M., Gutow, L., Klages, M. (Eds.), Marine Anthropogenic Litter. Springer, Berlin, pp. $1-25$.

Ryan, P.G., De Bruyn, P.N., Bester, M.N., 2016. Regional differences in plastic ingestion among Southern Ocean fur seals and albatrosses. Mar. Pollut. Bull. 104, 207-210.

Senthilnathan, L., Ranith, R., Machendiranathan, M., Dennis, A., 2018. Effect of Marine Litter on Palk Bay Corals in India. COMAD 2018. Marine Biological Association of India, pp. 86-87. 
Sruthy, S., Ramasamy, E.V., 2016. Microplastic pollution in Vembanad Lake, Kerala, India: The first report of microplastics in lake and estuarine sediments in India. Environ Pollut. 222, 312-322. http://dx.doi.org/10.1016/j.envpol.2016. 12.038 .

Tamara, S., Galloway, Cole, M., Lewis, C., 2017. Interactions of microplastic debris throughout the marine ecosystem. Nature Ecol. Evol. http://dx.doi.org/10. 1038/s41559--017--0116.

Thompson, R.C., 2015. Microplastics in the marine environment: Sources, consequences and solutions. In: M. Bergmann, M. Klages (Ed.), Marine Anthropogenic Litter. Springer, Berlin, pp. 185-200.

Thompson, R.C., Olsen, Y., Mitchell, R.P., Davis, A., Rowland, S.J., John, A.W.G., McGonigle, D., Russell, A.E., 2004. Lost at sea: where is all the plastic?. Science 304, 838. http://dx.doi.org/10.1126/science.1094559.

Van Cauwenberghe, L., Vanreusel, A., Mees, J., Janssen, C.R., 2013. Microplastic pollution in deep-sea sediments. Environ. Pollut. 182, 495-499.
Vasudeo, G., Saraswathi, V., Sridhar, K., Saravanan, R., Loveson, L., Edward, Thirumalaiselvan, S., 2018. Solid Waste Management in Rameswaram Island - Green Ramesawaram Project. COMAD 2018. Marine Biological Association of India, pp. 178-181.

Warburton, K., Blaber, S.J.M., 1992. Pattern of recruitment and resources use in a shallow-water fish assemblage in Moreton Bay, Quuensland. Mar. Eco. Prog. Ser. 90, 113-126.

Wieczorek, A.M., Morrison, L., Croot, P.L., Allcock, A.L., MacLoughlin, E., Savard, O., Brownlow, H., Doyle, T.K., 2018. Frequency of Microplastics in Mesopelagic Fishes from the Northwest Atlantic. Front. Mar. Sci. 5, 39. http://dx.doi.org/ 10.3389/fmars.2018.00039.

Wright, Rowe D., Thompson, R.C., Galloway, T.S., 2013. Microplastic ingestion decreases energy reserves in marine worms. Curr. Biol.. 